\title{
A FRANÇA E 0 ISLÃ: ANÁLISE DE UMA RELAÇÃO
}

\author{
Adrián Albala ${ }^{1}$ e Aline Burni ${ }^{2}$
}

O atentado de janeiro de 2015 contra o Jornal satírico Charlie Hebdo constitui o evento mais recente e violento, dentro de um histórico atual de relações complicadas e tensas que envolvem a sociedade francesa, o Islã e os muçulmanos.

Entretanto, qualquer interpretação do atentado como um ataque do Islã em sua totalidade contra a sociedade francesa ou, neste caso, contra representantes da liberdade de expressão e da sátira, constituiria um atalho analítico óbvio e grosseiro. Mesmo assim, vários intelectuais e políticos franceses analisaram, nos dias posteriores ao atentado, o acontecimento como a prova perfeita da incompatibilidade do Islã com os valores - subentendidos democráticos e cristãos - da sociedade francesa. Na mesma tonalidade, ao confirmar-se que os culpados pelo ato haviam nascido e crescido na França, diversos comentaristas alertaram sobre o risco da existência de uma "quinta coluna" dentro da própria sociedade francesa, formada por islamistas franceses que estariam prestes a conspirar contra a ordem pública.

Esses discursos alimentam uma sensação de "choque de civilizações", questionando o impacto da presença do Islã e dos muçulmanos dentro das sociedades europeias e francesa. De fato, os muçulmanos e o Islã, em geral, constituem, desde 2007, os maiores alvos das retóricas identitárias, primeiro da extrema-direita e logo por parte da direita mais tradicional. Diversos políticos, como Marine Le Pen (Frente Nacional FN) e Nicolas Sarkozy (União por um Movimento Popular - UMP), aumentaram sua popularidade ao reforçar, para não dizer "radicalizar", sua postura contra os

\footnotetext{
1 Doutor em ciências políticas (Universidade da Sorbonne), pesquisador em posdoutorado na Universidade de São Paulo, Núcleo de Pesquisas em Políticas Públicas (NUPPs). Contato: adrian.albala@gmail.com

2 Doutoranda em Ciência Política pela Universidade Federal de Minas Gerais, pesquisadora do Grupo “Opinião Pública: Marketing Político e Comportamento Eleitoral”. Contato: alineburni@gmail.com
} 
muçulmanos e o Islã, deixando em um segundo plano outros temas políticos mais tradicionais, como a luta contra a imigração ou as temáticas económicas.

Destarte, em que medida o muçulmano na França consistiria em um "problema"? Este breve artigo se propõe a reatualizar o contexto da percepção do Islã e dos muçulmanos na França. Mostraremos o caráter recente e fulgurante desta temática em termos políticos e societários.

\section{Avaliando o fenómeno do "problema do Islã"}

Em 2014, uma pesquisa do Instituto Ipsos Mori identificou que os franceses superestimam consideravelmente a presença de muçulmanos no país: a percepção mensurada entre os respondentes foi de $23 \%$ da população como sendo muçulmana, ao passo que o indicador real deste grupo corresponde a cerca de $8 \%{ }^{3}$ apenas. Como a legislação francesa não permite o recenseamento da população em termos religiosos e étcnicos, devido à concepção da nação como "única e indivisível”, não é possível se ter uma estimação precisa do número de muçulmanos que vivem no país. As aproximações oficiais do Ministério do Interior giram em torno de 4 a 6 milhões de cidadãos de "cultura muçulmana", sejam praticantes ou não da religião. Entretanto, a extrapolação da categoria de muçulmanos em termos "culturais" pode causar graves problemas de precisão, assim como problemas de compreensão. Não necessariamente as gerações de origem magrebina são aderentes à crença muçulmana e não obrigatoriamente os cidadãos de fé muçulmana são praticantes de tal religião.

Contudo, frequentemente a religião muçulmana é vista como incompatível com a sociedade francesa. Como podemos avaliar no Gráfico 1, segundo pesquisa de opinião realizada pelo Ifop em outubro de $2012^{4}, 43 \%$ dos entrevistados pelo instituto Ifop em 2012, segundo o mesmo estudo, disseram que a presença de uma comunidade muçulmana na França corresponde a uma ameaça para a identidade do país. Apenas $17 \%$ afirmam que tal presença é mais um fator de enriquecimento cultural e outros $40 \%$ declararam uma posição neutra.

3 Le Monde de 21/01/2015

$4 \mathrm{http}: / /$ www.lefigaro.fr/assets/pdf/sondage-ipsos-islam-france.pdf 


\section{Gráfico 1: Posicionamento sobre a presença do Islã como ameaça para a sociedade}

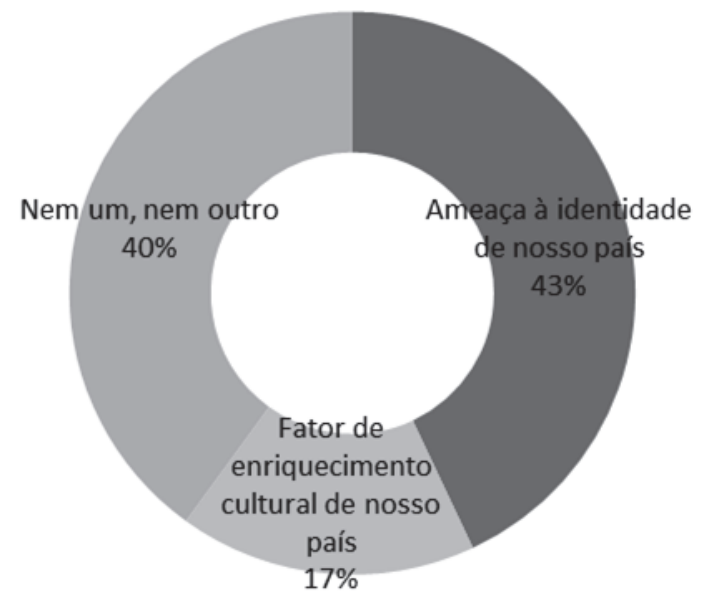

Fonte: Pesquisa de opinião pública “La perception de l’Islam par les Français”, Ifop, 2012.

Desta forma, é possível verificar que o suposto "problema do Islã" corresponde a uma percepção compartilhada por uma maioria relativa da sociedade francesa. A sensação de uma "invasão muçulmana", que colocaria em perigo a identidade francesa, parece, como outras percepções (a exemplo da sensação de insegurança), bastante exagerada quando confrontada com a realidade dos dados.

\section{As percepções da sociedade francesa sobre a religião muçulmana}

No entanto, não é de se surpreender que essas sensações sejam tão fortes na França. 0 país tem certamente fortes raizes cristãs. Também, o forte arraigamento da laicidade na sociedade francesa, junto com uma proporção importante de atéus ${ }^{5}$, confere um certo escepticismo frente às religiões em geral. Contudo, aparece lógico que a percepção do Islã como religião "importada", e a manifestação do pertencimento ou identificação com o islã, em recrudescência dede os anos 1980, tenha um teor relativamente negativo. Assim como em outros países, as atitudes anti-Islã aumentaram em vários setores sociais após os atentados terroristas de 11 de setembro ocorridos nos

5 Segundo os estudos da WIN/Gallup de 2012 e 2014, a França é o quarto país "mais ateu" do mundo. 
Estados Unidos. Entretanto, o evento atuou mais como um amplificador do que um deflagrador da Islamofobia, posto que, em função das relações históricas com a antiga colônia Argélia e de subsequentes eventos de matanças de civis ocorridos naquele país durante a década de 1990, o Islã foi frequentemente relacionado ao terrorismo fundamentalista e à violência em geral pela opinião pública francesa (Geissier, 2010).

Para muitos franceses é, ainda, bastante confusa a fronteira entre imigração, religião muçulmana e islamização - ponte simplificada de ligação com o radicalismo e com o terrorismo. Destarte, quando se analisam os índices de percepção do Islã por parte da sociedade francesa, a noção mais frequente associada à ideia que se tem do Islã na França é a rejeição dos valores ocidentais (28\%), seguido de fanatismo (19\%) e submissão (18\%), conforme observado no gráfico 2.

\section{Gráfico 2: Noções mais associadas ao Islã (\%)}

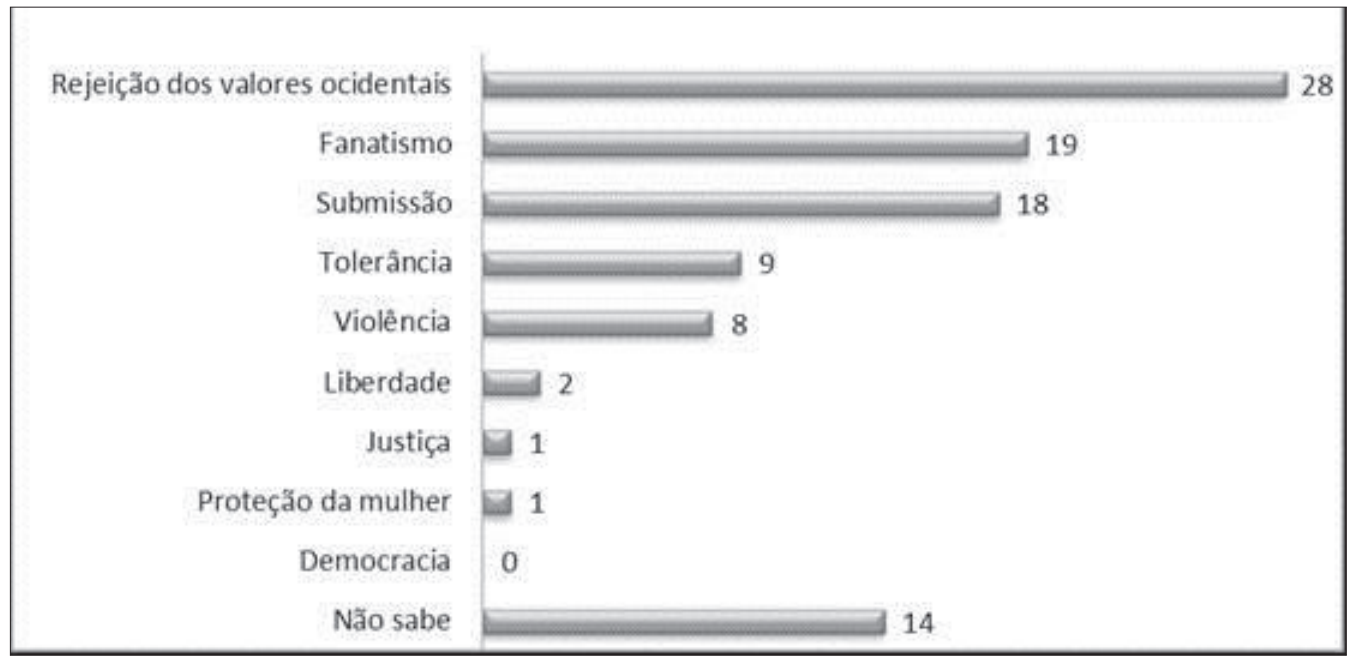

Fonte: Pesquisa de opinião pública “La perception de l’Islam par les Français”, Ifop, 2012.

Como já vimos, essas percepções são o fruto de sensações amplamente exageradas, pois o contato da sociedade francesa com o Islã é relativamente baixo, devido ao baixo número, aproximativo, de muçulmanos no país. Os adjetivos listados no Gráfico 2 e o seu grau de identificação aparecem, portanto, amplamente influenciados pelo contexto internacional pós 11 de setembro de 2001. Entretanto, a convivência da sociedade francesa com o Islã é antiga e atualmente tal relação apresenta um permanente paradoxo. Conforme explica Vincent Geisser (2010, p. 5), é possível identificar avanços na institucionalização do Islã, alternativamente a repressões reais e 
simbólicas. Como religião de uma minoria, o Islã é tolerado e protegido. Mas, ao mesmo tempo, esta tolerância fria também incentiva os muçulmanos a gradualmente abandonarem suas "atitudes comunitaristas", que significam a prevalência das regras e modos de vida de uma comunidade sob os indivíduos que dela fazem parte. De acordo com a definição de Laurent Bouvet (2007): “Le communautarisme est un système social et politique, c'est un ensemble de règles qui privilégient l'intérêt de la communauté sur celui des individus qui la composent. La communauté subjugue l'individu"6.

Por outro lado, se consideramos que a França não é, historicamente, uma terra do Islã, ou seja, que a prática crescente do Islã e, concomitamente, o número de muçulmanos, estão intimamente vinculados com ondas de imigração de pessoas provindo de culturas muçulmanas, é de se esperar que a antipatia vis-a-vis do Islã cresca em função de considerações ideológicas sobre a imigração.

Esta temática da imigração foi fortemente introduzida no debate político-eleitoral pelo partido de extrema-direita Frente Nacional, criado em 1972, liderado por quase quarenta anos pelo polêmico dirigente Jean-Marie Le Pen e hoje "desdiabolizado" por sua herdeira, Marine Le Pen (Ivaldi 2012, Crépon et al. 2015). A progressiva popularidade da Frente Nacional nos últimos anos é sintomática da visão de que existem grupos opostos na população do país, cujos valores são conflitivos e incompatíveis. Comumente, os muçulmanos são associados muito mais à imigração do que à comunidade francesa, pois são vistos como uma categoria diferente por significativa parcela do eleitorado, cujasorientações valorativas xenófobas, conservadoras e nacionalistas influenciam fortemente o voto.

Destarte, se relacionarmos a percepção do islã, como religião, com as preferências ideológicas, observamos, no Gráfico 3, que os eleitores do FN demonstram efetivamente uma percepção muito mais negativa acerca desta religião do que os eleitores de esquerda ou mesmo de direita, que tendem a ser mais conservadores do que os esquerdistas. Em 2012, mais da metade dos votantes de Marine Le Pen $(54,1 \%)$ afirmaram considerar o Islã como algo "muito negativo", segundo a pesquisa póseleitoral Enquête Électorale Française de 2012. Estes dados fornecem evidência suplementar para a natureza cultural das razões da percepção negativa acerca da imigração por parte dos eleitores frentistas. Não é necessariamente por representar

\footnotetext{
${ }^{6}$ Politique Autrement, abril 2007. Disponível em http://www.politique-autrement.org/Lettre-no-41-Lecommunautarisme-mythe-ou-realite
} 
uma ameaça econômica que tais eleitores se opõem ao fenômeno da imigração e do multiculturalismo, mas sim devido ao fato de que estes elementos ameaçam a identidade nacional e a tradição do país, fatores que devem ser preservados na visão desses eleitores.

No entanto, quando comparamos com os outros eleitorados, chama a atenção que o Islã seja, em geral, negativamente percebido, inclusive pelo eleitorado de esquerda (61,5\% possui percepção negativa). Quanto aos eleitores da direita tradicional, os resultados são muito similares aos dos eleitores da Frente Nacional, evidenciando uma permeabilidade dos dois eleitorados sobre essa temática da percepção do Islã.

\section{Gráfico 3: Percepção do Islã na França, por auto-localização ideológica}

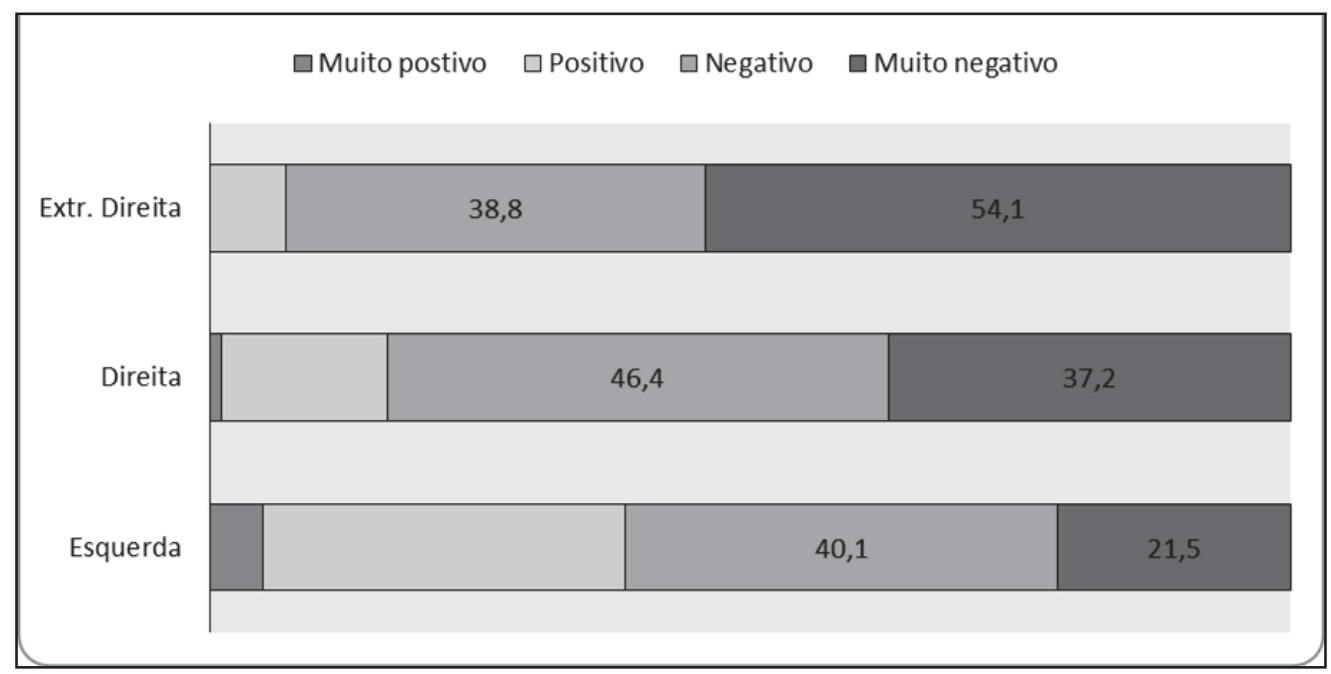

Fonte: Pesquisa Enquête Électorale Française de 2012

Pensando nas parcelas da população mais concernidas pela temática, os jovens parecem ser a geração mais "polarizada" sobre a questão. Isso indica a existência de possível efeito geracional de "ondas de valores". Ao mesmo tempo em que ser jovem apresentou correlação positiva com as chances de se votar em Marine Le Pen nas presidenciais de 2012, tanto comparado com o voto na esquerda, quanto ao voto na direita segundo análise realizada por Burni (2015), é também entre os jovens que a prática da identidade muçulmana tem apresentado uma afirmação mais forte. 0 voto na extrema-direita mostrou-se correlacionado, sobretudo, com valores xenófobos, eurocépticos e conservadores. Isso nos levaria a pensar que parcela dos jovens se torna cada vez mais nacionalista, intoleRante e radical. De um lado, tais atitudes se voltariam 
para a adesão às teses da extrema-direita. De outro, alimentaria o apoio ao Islã radical como forma de afirmar uma identidade alternativa e conflitiva com a tradição europeia cristã.

De fato, o Jihadismo tem conquistado, principalmente, jovens para deixarem seus países de origem e combaterem em nome de Ala. Muitas vezes os recrutados possuem um conhecimento extremamente limitado sobre o Islã, mas se engajam em aventuras terroristas motivados por frustrações sociais ou psicológicas. Segundo especialistas, um forte sentimento de exclusão social, econômica e política explica porque jovens cidadãos são atraídos pelas ideias jihadistas ${ }^{7}$. A emergência de uma cultura fundamentalista, radical em relação ao Islã, muitas vezes tomada como oposta aos valores da República, pode ser explicada como resultado de um sentimento de relegação social. Em 2013 o sociólogo Hugues Lagrange publicou estudo que indicava esta tendência geracional. Segundo o estudioso, "La résurgence des pratiques cultuelles et la religiosité augmentent chez les immigrés venus en France avant l'âge de 16 ans et chez les Français descendants d'immigrés, mais pas chez les immigrés arrivés à l'âge adulte"8

\section{0 "problema do islã": um fenômeno recente}

Até a queda do muro de Berlim, a politica francesa esteve essencialmente marcada por debates de ordem materialista (Estado-Mercado). Desse período até os 1990 as temáticas da religião e da imigração não eram elementos centrais do debate político, o que explica os resultados limitados da Frente Nacional até 1995. Até então a relação dos franceses com o Islã era percebida essencialmente através da temática da imigração em geral e como fruto da importação do conflito Israelo-Palestino para o interior das fronteiras francesas.

De fato, até então, os alvos dos discursos do principal partido de extrema-direita, Frente Nacional, para justificar os problemas do país eram, juntos, a União Europeia, os judeus e os "imigrantes" em geral, sem distinção religiosa particular.

\footnotetext{
720 Minutes, 03 de julho de 2015. Disponível em < http://www.20min.ch/ro/news/monde/story/Lexclusion-des-jeunes-nourrit-le-jihadisme-25317533>

$8 \quad$ Le Monde, 01 de novembro de 2012. Disponível em <http://www.lemonde.fr/culture/article/2012/11/01/des-jeunes-fideles-a-l-islam_1784520_3246.html>
} 
No que diz respeito ao Islã, o primeiro acontecimento midiático sobre o lugar do Islã na sociedade -laica- francesa, aconteceu em 1989, com o caso de duas meninas francesas que tinham sido barradas na entrada do colégio por usarem um véu islámico (hijab). Uma série de atentados que impactaram a França entre os anos 1994 e 1995 começaram a colocar o Islã dentro da agenda política. A percepção e vinculação do Islã e do Islamismo como potenciais ameaças à ordem pública se evidenciaram recentemente com os eventos de 2001.

Contudo, é apenas em 2005, que um candidato nacionalista, Philippe De Villiers se apresenta, pela primeira vez, com um discurso "contra a islamização da França". Esse discurso ganhou forte adesão e foi retomado pela nova presidente da Frente Nacional, Marine Le Pen. Tanto que hoje em dia, a "ameaça islamista" constitui o principal argumento da extrema-direita, a partir do qual o partido tem registrado as maiores conquistas eleitorais da sua história.

Mesmo que a imigração ainda seja tratada como intrinsecamente vinculada aos problemas socioeconômicos como o desemprego e a criminalidade pelo partido de extrema-direita francês, o discurso de Marine Le Pen começou a dar uma atenção especial à temática da imigração e à presença de muçulmanos enquanto ameaça cultural à nação e tradição francesas. Nesse sentido, o tema da "islamização da França", é evidenciado como um fenômeno de invasão demográfica e ideológica do país pela religião muçulmana. 0 republicanismo e a laicidade se tornam elementos importantes na construção de uma oposição cultural entre as civilizações francesa e muçulmana, posto que tais conceitos representam os valores democráticos, nacionais, de tolerância e de distinção entre Estado e religião, o que não está associado ao Islã, no discurso de Marine Le Pen. Na interpretação do FN, a religião muçulmana representa aquilo que é contrário aos valores da sociedade francesa e da civilização europeia de forma geral, pois está essencialmente vinculada ao terrorismo, à violência, ao extremismo, à intolerância, ao desrespeito dos direitos individuais e ao fundamentalismo religioso.

Com a fidelização do eleitorado da frente nacional, desde 1995 e o "ápice eleitoral" de 2002 (Jean Marie Le Pen conseguindo se classificar para o segundo turno das eleições presidenciais daquele ano) a importância de seduzir ou (re)conquistar o eleitorado de extrema-direita apareceu, para uma parte da direita tradicional, como uma estratégia necessária para se manter no poder. Daí que a temática do Islã e do suposto "problema do Islã" foi amplamente recuperada por interlectuais e políticos de direita 
mais tradicional. Não apenas a elite política é responsável pela introdução do debate do Islã na agenda política a partir de um viés negativo e ameaçador, mas a elite intelectual também contribuiu consideravelmente para a legitimação da visão atrasada e incompatível do Islã quando confrontada à civilização francesa (Geisser, 2010, p. 8):

\begin{abstract}
French islamophobia can probably be characterized by its intellectual and elitist dimension. The direct or indirect fallouts of the widely publicized debates about the prohibition of the Islamic veil within public school premisses (Stasi's Commission on the wearing of religious signs) played a significant role in " facilitating » a latent islamophobia: Opinion leaders (journalists, editorialits, philosophers, security experts, etc.) are the main vectors of this latent islamophobia which takes advantage of the right to criticize religions and the freedom of conscience to draw stigmatizing representations of Islam and Muslims. Islamophobia is thus taken over and further supported by some representatives of the French elites who are therefore directly contributing to its justification among various social groups. To some extent, they are indeed promoting a liberalization and trivialization of the islamophobic thesis.
\end{abstract}

De fato, Nicolas Sarkozy, usou de forma repetida alguns discursos e posicionamentos ambíguos sobre a compatibilidade entre Islã e a tradição francesa de tradição judaico-cristã⿱9. Contudo, esse "choque de civilizações" que ameaçaria as tradições e a cultura francesa constitui hoje em dia um dos principais temas do debate no país (Burni, 2015).

Como ilustrativo disso, podem ser citados sucessos de venda dos livros do ensaísta e intelectual de direita, Eric Zemmour. O seu último livro "O suicídio francês", o maior êxito nas livrarias em 2014, retrata uma suposta decadência da França iniciada há 40 anos devido, essencialmente, as políticas imigratórias que facilitaram a entrada de populações não ocidentais, favorecendo a dissolução dos valores franceses (Albala, 2015). Nesta mesma onda está o famoso novelista Michel Houellebecq, que tem reiterado em vários de seus livros a sua islamofobia e publicou em janeiro de 2015 um livro sobre as consequências da suposta vitória de um candidato muçulmano nas eleições presidenciais de 2022. De fato, irônica e paradoxalmente, a capa de Charlie Hebdo que sairia no dia do atentado continha uma charge contra Houellebecq sobre o conteúdo ideológico de seu livro.

A estratégia eleitoral da Frente Nacional sob Marine Le Pen, parece, desta forma, ter sido um sucesso. A sua retórica tem sido capaz de distorcer o discurso republicano e em defesa da laicidade em favor do nacionalismo, pois a defesa dos valores nacionais,

\footnotetext{
${ }^{9}$ Adrián Albala "Análise: Ex-presidente Sarkozy terá retorno político delicado na França" Folha de São Paulo, 09/12/2015
} 
em oposição ao "comunitarismo" e à ditadura da religião na vida social - supostamente característicos dos grupos muçulmanos - se coloca justamente em oposição aos supostos valores do Islã. Há um esforço em mascarar a orientação islamofóbica do partido através de referências à herança republicana (Ivaldi, 2012), de forma que a contraposição ao Islã é considerada ato de defesa dos valores Republicanos.

Observamos, assim, um descolamento das percepções de temática conexas ao Islã, precisamente a partir de 2007, resultado de uma absorção crescente de uma parte significativa da sociedade francesa pelas teses lepenistas. De fato, conforme demonstrado no Gráfico 4, a opinião dos franceses contrária à construção de mesquitas no país passou de 38\% para 43\%, ou seja, houve um aumento de 5 pontos percentuais dentro do período considerado. Se tal progressão não aparenta ser estrondosa, deve-se atentar para a significativa queda das posições favoráveis à construção de mesquitas na França, que passou de 33\% em 1989 para apenas 18\% em 2012, seja uma diminuição de 15 pontos percentuais em aproximadamente três décadas.

\section{Gráfico 4: Posição sobre a construção de mesquitas no país (\%)}

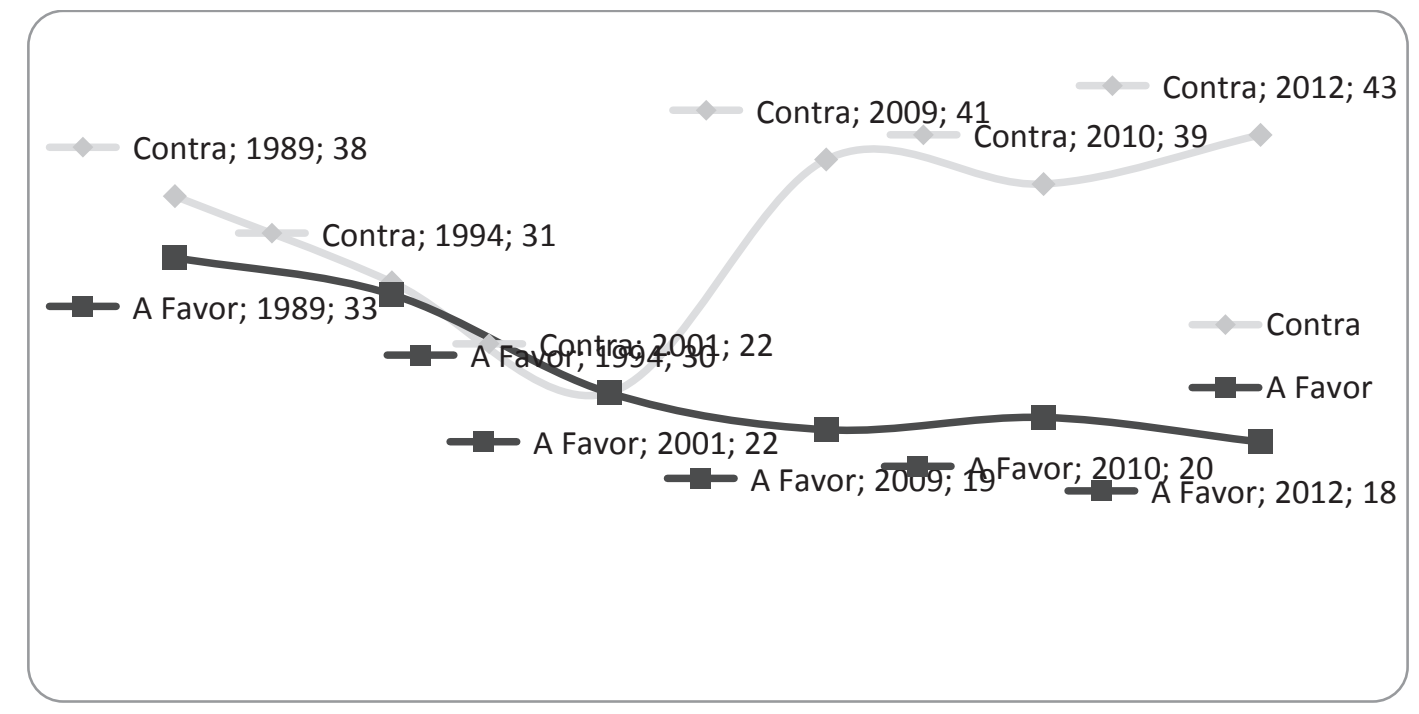

Fonte: Pesquisa de opinião pública “La perception de l’Islam par les Français”, Ifop, 2012.

Da mesma forma, no que se refere ao uso do véu nas ruas, outro símbolo importante do Islã, também se observa uma redução da tolerância dos franceses com o passar do tempo. A categoria de respondentes contrários a esta prática passou de 31\% em 1989 para 63\% em 2012. De acordo com o gráfico abaixo, houve uma significativa evolução desta posição no ano de 2010, período em que foi votada a lei de interdição do 
véu integral em espaços públicos sob o governo de Nicolas Sarkozy (UMP). Na visão de Geisser, a islamofobia se confunde com a oposição ao uso do véu pelos praticantes de tal religião, pois muitos dos opositores a este adereço justificam a rejeição com base em valores seculares e em defesa da igualdade entre homens e mulheres. 0 hijab é visto, por muitos, como uma expressão do islamismo ameaçador, como um símbolo do fundamentalismo islâmico, que confronta os valores seculares e republicanos básicos da sociedade francesa (Geisser, 2010, p. 8). Nesse sentido, o uso do hijab é interpretado não como o direito da expressão individual de crenças e valores particulares, mas como um perigo social e um problema de segurança pública. A criminalização do hijab faz com que as mulheres que o vestem sejam percebidas como ofensoras (Geisser, 2010, p. 7).

Gráfico 6: Posição sobre o uso do véu nas ruas - hijab (\%)

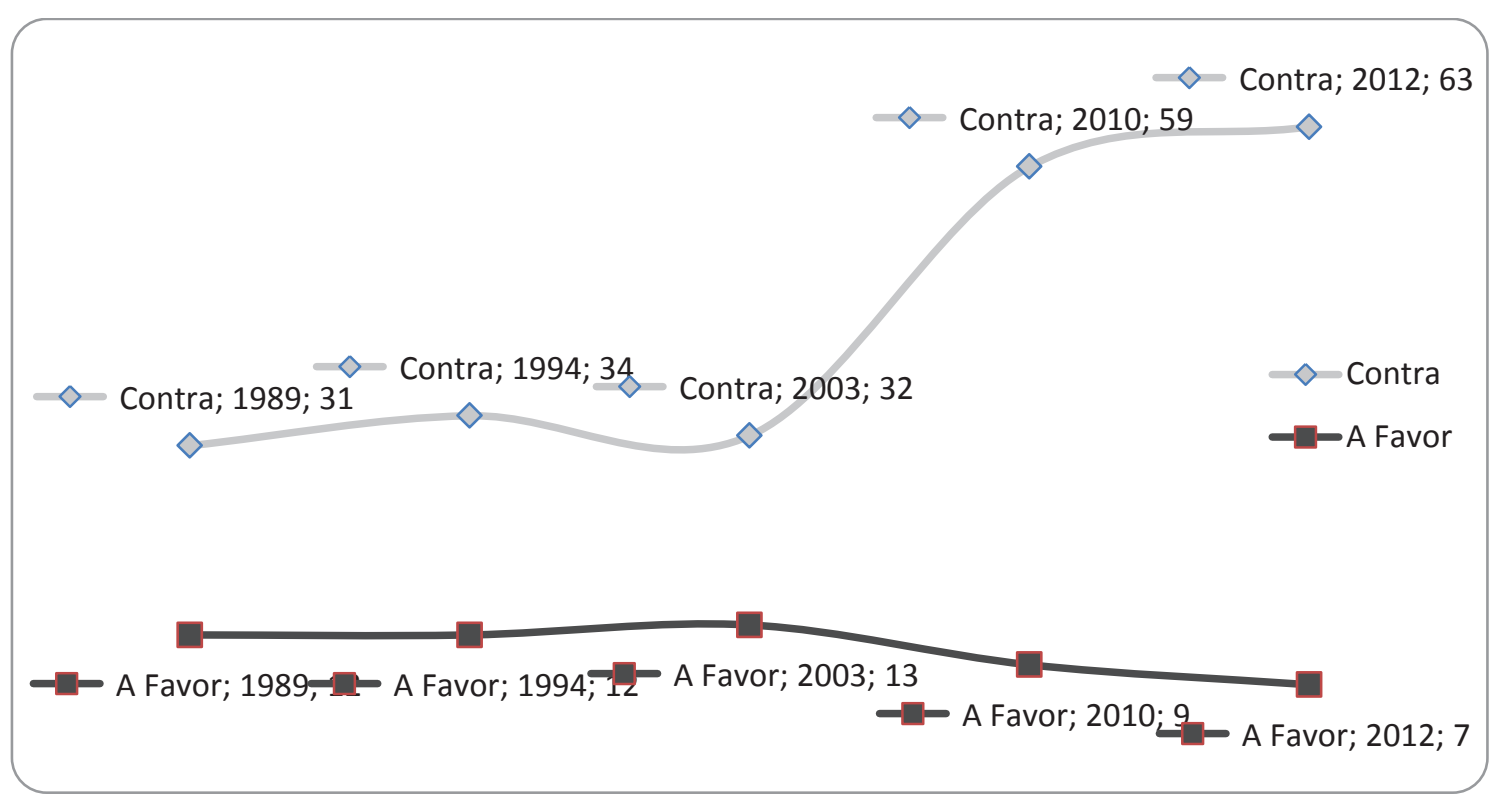

Fonte: Pesquisa de opinião pública “La perception de l'Islam par les Français”, Ifop, 2012.

\section{Conclusão}

Por muito tempo, a sociedade francesa não parecia atribuir ao islã o papel negativo que ele parece ter hoje. A evolução recente das percepções é, destarte, o fruto de uma mudança nas considerações sociais e políticas, acentuadas pela perda de dinamismo econômico e o declínio da influência do país no cenário internacional. 
Contudo, a identificação do Islã como a principal ameaça interna à identidade francesa, que vem crescendo de forma mais expressiva desde 2007, é fruto da representação cunhada pelas elites políticas, pela mídia e pelos intelectuais, que convergem em direção a uma concepção assimilacionista do Islã, segundo a qual a expressão da religiosidade é reduzida ao mínimo e o Islã é concebido como uma religião "atrasada", incompatível, em oposição aos modernos valores seculares e republicados (Geisser, 2010, p. 4). Dentre tais estratégias de legitimação da visão negativa do Islã, destaca-se a estratégia de reorientação eleitoral do principal partido de extrema-direita francês, a Frente Nacional, que conseguiu permear uma parcela importante do eleitorado da direita tradicional. Frente a essa massificação de discursos de tom anti-islã e a sua progressão na sociedade francesa em geral, a esquerda política e intelectual não conseguiu oferecer um posicionamento alternativo à visão assimilacionista do Islã, limitando-se às defesas frágeis das minorias étnicas, religiosas e dos imigrantes, de caráter humanista. 0 problema não deveria ser concebido como do Islã frente às sociedades ocidentais, mas sim um problema dentro do próprio Islã, cujas vertentes são múltiplas e variadas. Cabe à esquerda adotar um posicionamento mais claro e inteletualizado, se ela não deseja ser absorvida pelas posições mais radicais e perder completamente o controle da agenda sobre as temáticas valorativas e sociais. A temática do Islã se torna ainda mais importante com os acontecimentos recentes de ondas de refugiados, principalmente sírios e afegãos, que chegam à Europa. Políticos como o expresidente Nicolas Sarkozy já se posicionaram para fazer frente a essas ondas, manifestando-se a favor da reconsideração dos acordos de Schengen sobre a livre circulação dos cidadãos dentro das fronteiras da União Europeia e uma reforma do jus solis (obtenção da nacionalidade a partir do nascimento na França). Essas propostas se assemelham muito às da Frente Nacional. Enquanto isso, a esquerda permanece sem posicionamentos e propostas claras, em um período crítico de crise econômica no qual ocupa o governo e, ainda, detém baixíssima popularidade. 


\section{Referências}

ALBALA, Adrián. "Atitude anti-islã cresce entre intelectuais e políticos franceses". Folha de São Paulo, 12 jan. 2015.

CREPON, S., DÉZÉ, A., e MAYER, N. Front national, les faux-semblants Sociologie d'un parti politique, Paris: Presses Nationales de Sciences-Po, 2015

BURNI, Aline. Extrema-direita e os "perdedores da globalização": preditores do voto em Marine Le Pen nas presidenciais francesas de 2012. Tese de Mestrado, Universidade Federal de Minas Gerais, Belo Horizonte, 23 de fev. 2015

GEISSIER, Vincent. "Intellectual and Ideological Debates on Islamophobia: A 'French Specificity' in Europe?" Human Architecture: Journal of the Sociology of SelfKnowledge, 2010.

IFOP, L'image de l'Islam em France, out. 2015.

IVALDI, G. Permanences et évolutions de l'idéologie frontiste. In : DELWIT, P. (Ed.). Le Front National. Mutations de l'extrême droite française. Bruxelles : Éditions de l’Université de Bruxelles, 2012. 95-112.

JOIGNOT, F. "En France, des jeunes de plus em plus fidèles à l'islam” Le Monde, Paris, 01 nov. 2012

POUCHARD, A.; LAURENT, S. “Quel est le poids de l'islam em France?”. Le Monde, Paris, 18 jun. 2015 